\title{
Forest fires cause pollution crisis in Asia
}

[TOKYO] The Malaysian government last week declared a state of emergency in Sarawak, on the island of Borneo, as smoke pollution from forest fires burning out of control in neighbouring Indonesia enveloped many cities in South-East Asia. In Sarawak, the pollution reached life-threatening levels, forcing schools, factories and offices to shut.

Fires set off by the slash-and-burn activities of plantation owners and farmers in Indonesia are raging out of control in an arc extending around the Malay peninsula from Sumatra through Java to Kalimantan in Borneo and Sulawesi. The fires have been exacerbated by drought thought to have been brought on by what is proving to be one of the most severe El Niño episodes on record.

The situation in Sarawak is particularly severe, as pollution levels have gone off standard scales of measurement, and visibility has been reduced to tens of metres. A state of emergency has been declared, and the 1.9 million people in Sarawak have been advised to stay indoors with windows and doors shut.

Pollution also briefly reached hazardous levels last week in Kuala Lumpur on the west side of the Malay peninsula, and has risen to unhealthy levels in Singapore.

The Indonesian government considered evacuating the city of Rengat in Sumatra, where visibility at one point dropped to a few metres, and people were having difficulty breathing. But these plans have been tem-

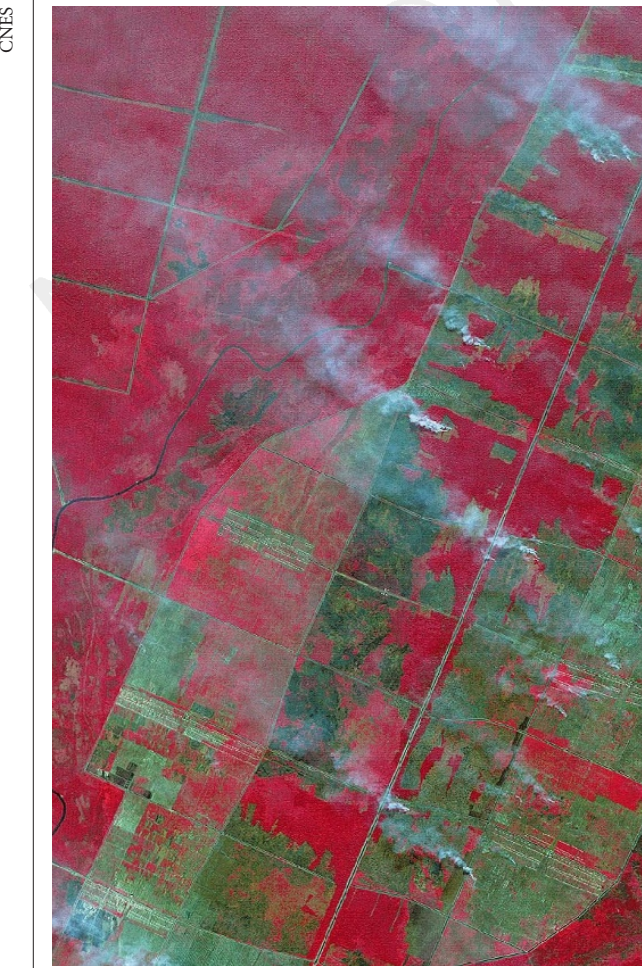

Burning issue: damage to vegetation in the

Indonesian forests has been assessed from satellite pictures analysed by CRISP at the National

University of Singapore. (Distributed by SPOT IMAGE/SPOT ASIA)

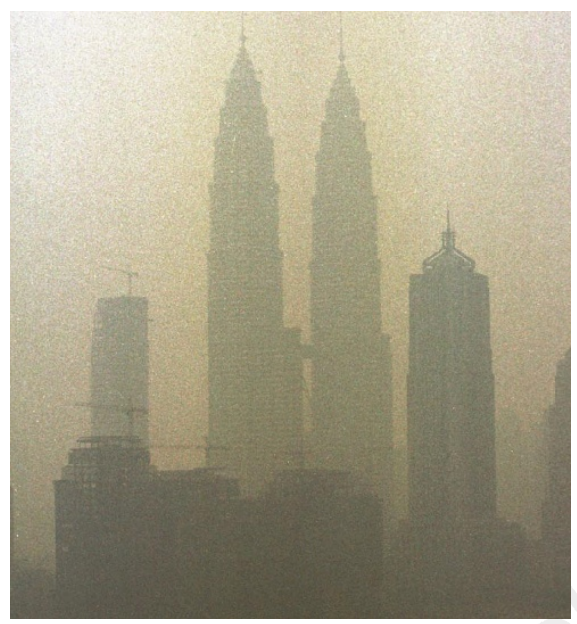

Smoky city: air pollution in Kuala Lumpur in Malaysia rose to dangerous concentrations.

porarily abandoned because the situation improved with a change of wind.

Last week, President Suharto of Indonesia apologized to environment ministers from the East Asian region at a meeting in Jakarta, and his government has banned plantation owners and forestry companies from using fire to clear forest.

But a spokesman for the Indonesian government's Environmental Impact and Assessment Agency, quoted in the Straits Times of Singapore, said satellite pictures showed that the number of new fires had increased since the ban, as companies rushed

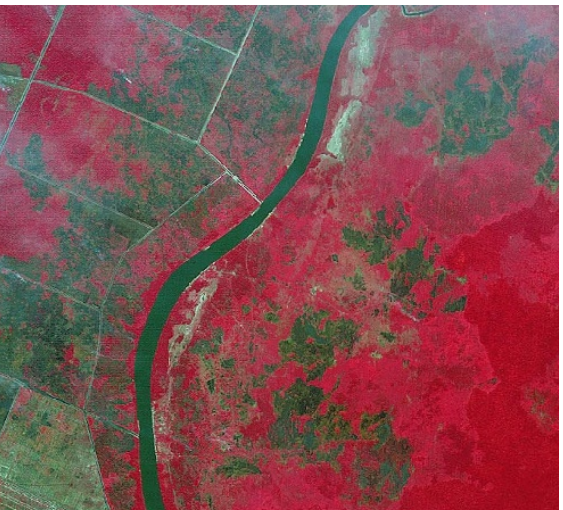

to clear forest before the clampdown.

At least 70 major fires are raging out of control in Kalimantan and central and southern Sumatra. Satellite images obtained by the Centre for Remote Imaging and Sensing (CRISP) of the National University of Singapore show that more than half of the vegetation in southeast Kalimantan has been destroyed by slash-and-burn clearing in the past three months. The Indonesian air force is flying sorties in Kalimantan and Sumatra to seed clouds to induce rain to help clear the pollution.

Datuk Chua Jui Meng, the Malaysian minister of health, reported that more than 8,000 people in Malaysia had been admitted to hospital with health problems related to the pollution.

The Environment Ministry in Singapore has announced that if the Pollutants Standard Index, a measure of the level of various pollutants in the atmosphere devised by the US Environment Protection Agency (see box), reaches the "hazardous" level of 300, schools and sports complexes will be closed down. If it reaches the "life-threatening" level of 400, civil defence sirens will sound and emergency radio broadcasts will be made.

Singapore has not so far been as badly affected as Malaysia and Indonesia because winds are blowing most of the smoke into Malaysia. Nevertheless, the index reached an all-time high of 226 in Singapore for a 3-hour period last Thursday, a level classed as "very unhealthy" under the US measure.

Malaysia uses a slightly different scale for measuring pollution called the Air Pollution Index. But it is based on the same principles and yields similar though slightly higher numbers to the Pollutants Standard Index (see panelbelow).

In Sarawak, the Air Pollution Index hit 658 in Kuching when the government declared a state of emergency. This may be the highest level of pollution ever recorded, as it exceeds the highest level of 500 on the US scale.

DavidSwinbanks

\section{Air pollution index indicates danger levels}

[TOKYO] The Pollutants Standard Index (PSI), devised by the US Environment Protection Agency, is based on the levels of five pollutants in the atmosphere - ozone, nitrogen dioxide, sulphur dioxide, carbon monoxide and particulate matter.

The concentration of each is measured and converted to a number on a scale of 0 to 500 . The highest of the five numbers sets the reading. The range 0 to 50 is classed as "good", 51 to 100 is "moderate", 101 to 200 is "unhealthy", 201 to 300 is "very unhealthy", more than 300 is "hazardous" and levels over 400 can be lifethreatening to the ill and elderly and those who have respiratory problems such as asthma.

Malaysia uses a slight modification of this index called the Air Pollution Index. The scale is the same as the PSI up to 50, but then diverges to slightly higher numbers. For example, a PSI of 200 converts to about 257 on the Malaysian scale and 500 to about 577. Sarawak, where a state of emergency has been declared, recorded a maximum of 658 last Friday. D.s. 